\title{
NASA Goddard Space Flight Center's Compendium of Recent Total lonizing Dose and Displacement Damage Dose Results
}

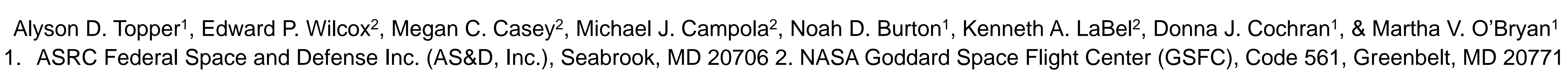

Abstract: Total ionizing dose and displacement damage dose testing were performed to characterize and determine the suitability of candidate electronics for NASA spacecraft and program use.

\begin{tabular}{|c|c|}
\hline \multicolumn{2}{|c|}{ Introduction } \\
\hline \multicolumn{2}{|c|}{$\begin{array}{l}\text { Long term radiation-induced failure modes play a } \\
\text { significant role in determining space system reliability. In } \\
\text { order to determinete risk to spaceflight applicacitions, the } \\
\text { effects of total ionizing dose (TID) and displacement } \\
\text { damage dose (DDD) need to be evaluated through } \\
\text { ground-based testing. }\end{array}$} \\
\hline \multicolumn{2}{|c|}{ 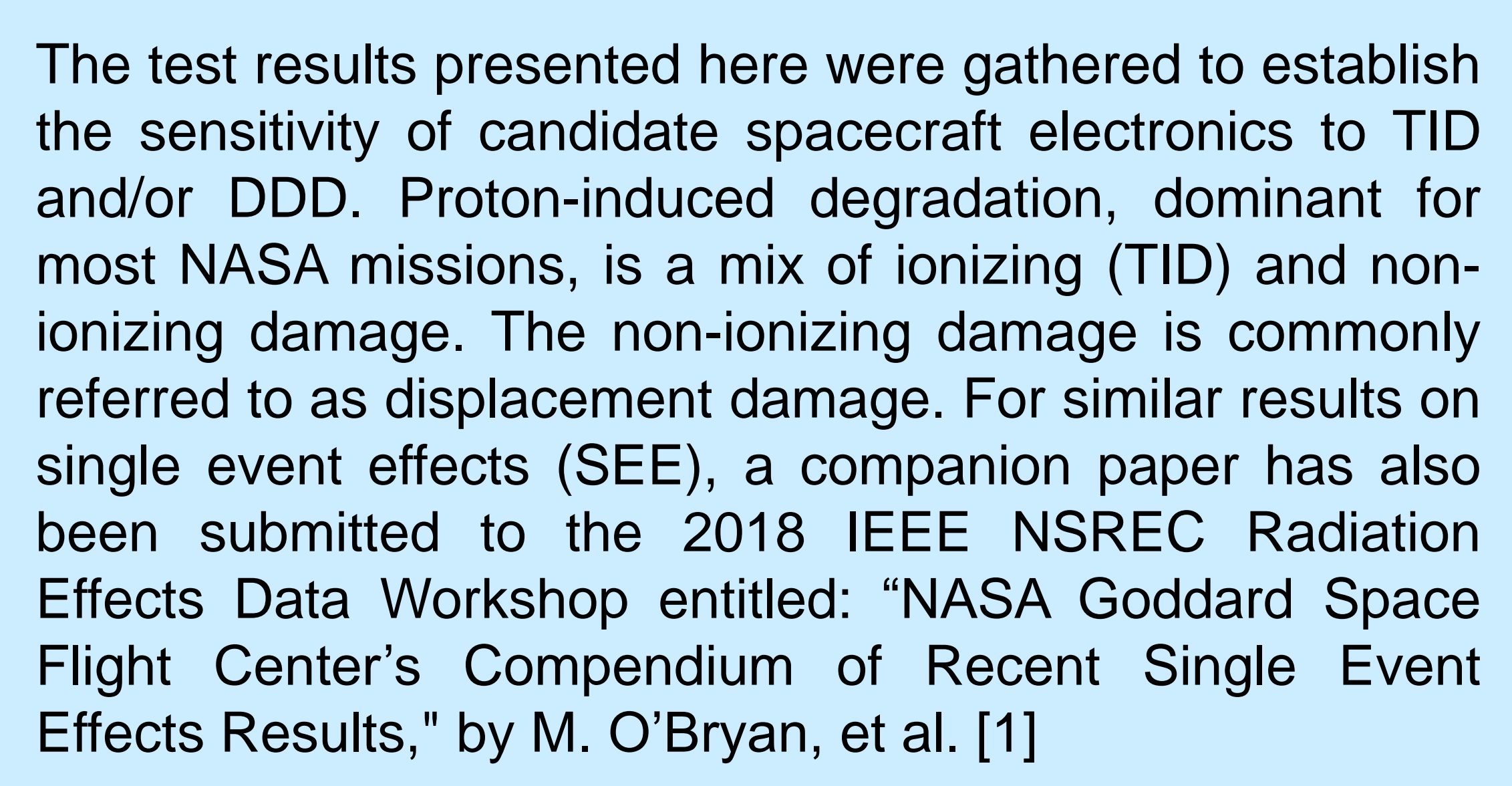 } \\
\hline \multicolumn{2}{|c|}{$\begin{array}{l}\text { This paper is a summary of results. Pleasen note that these } \\
\text { test results can depend on operational conditions. }\end{array}$} \\
\hline \multicolumn{2}{|c|}{ Proton Test Facility } \\
\hline \multicolumn{2}{|c|}{ 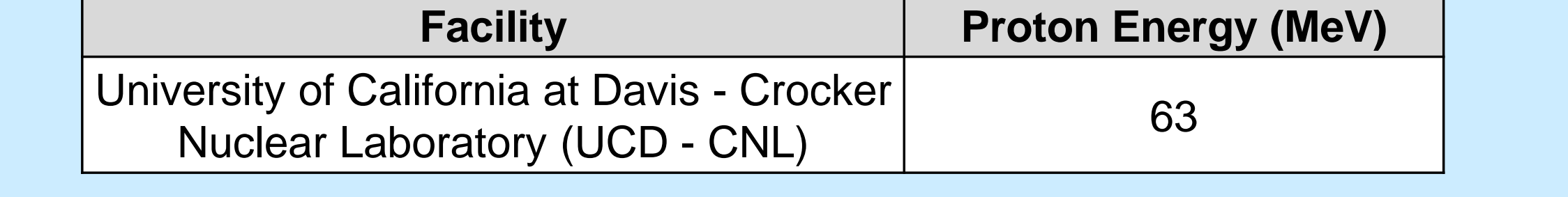 } \\
\hline \multicolumn{2}{|c|}{ Pls Coordinating Testir } \\
\hline \begin{tabular}{|c|c} 
Abbreviation & Prit \\
ADT & \\
MCC & \\
MJC & \\
\end{tabular} & 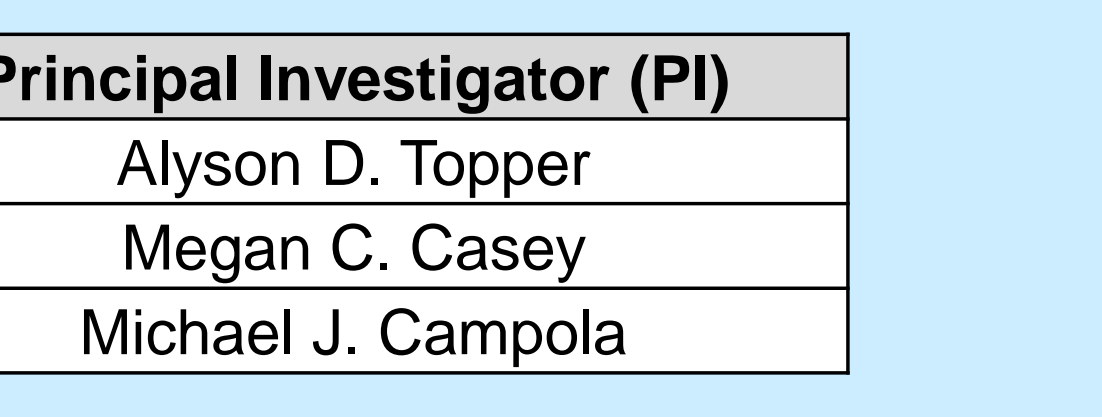 \\
\hline \multicolumn{2}{|c|}{ Acronyms } \\
\hline 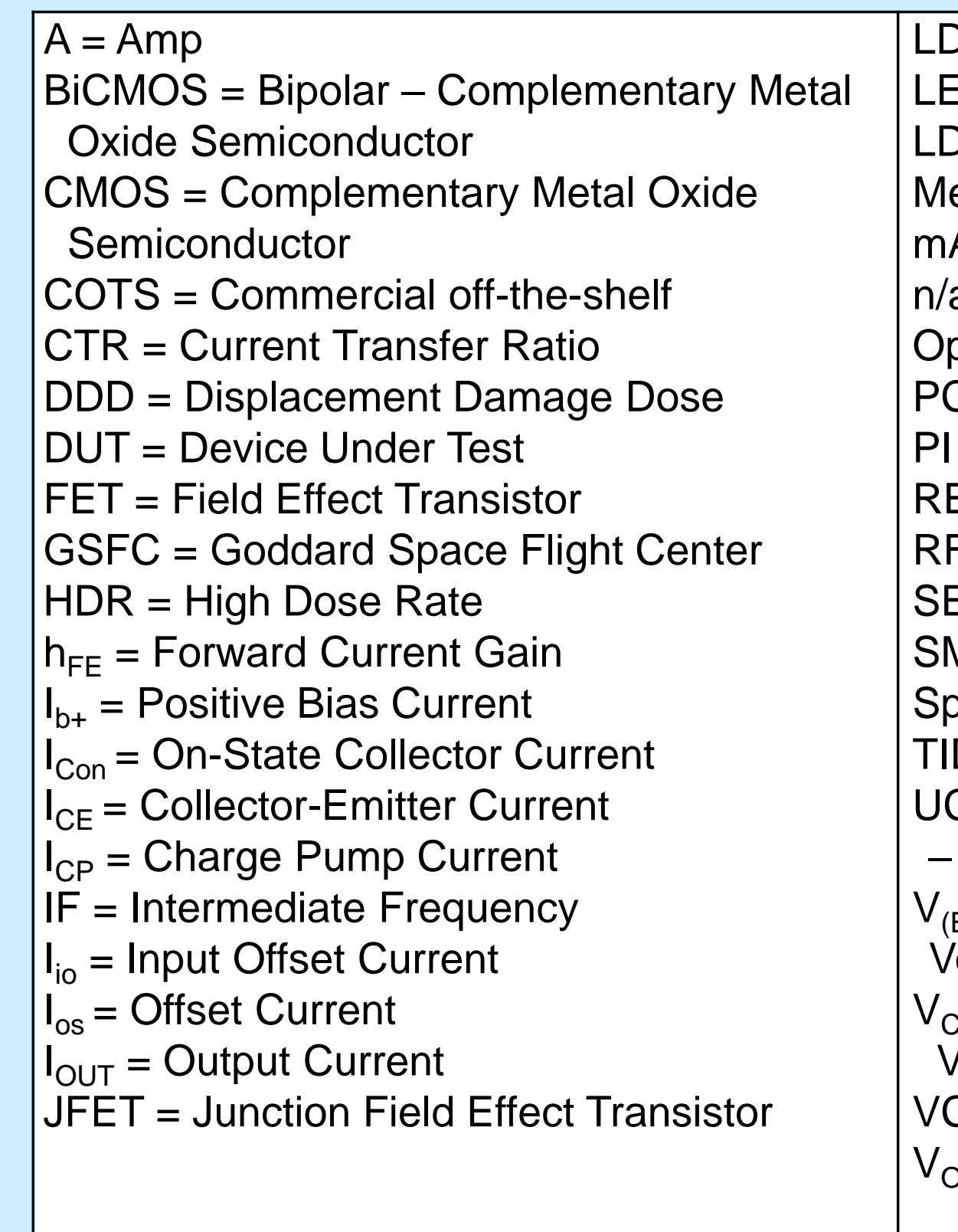 & 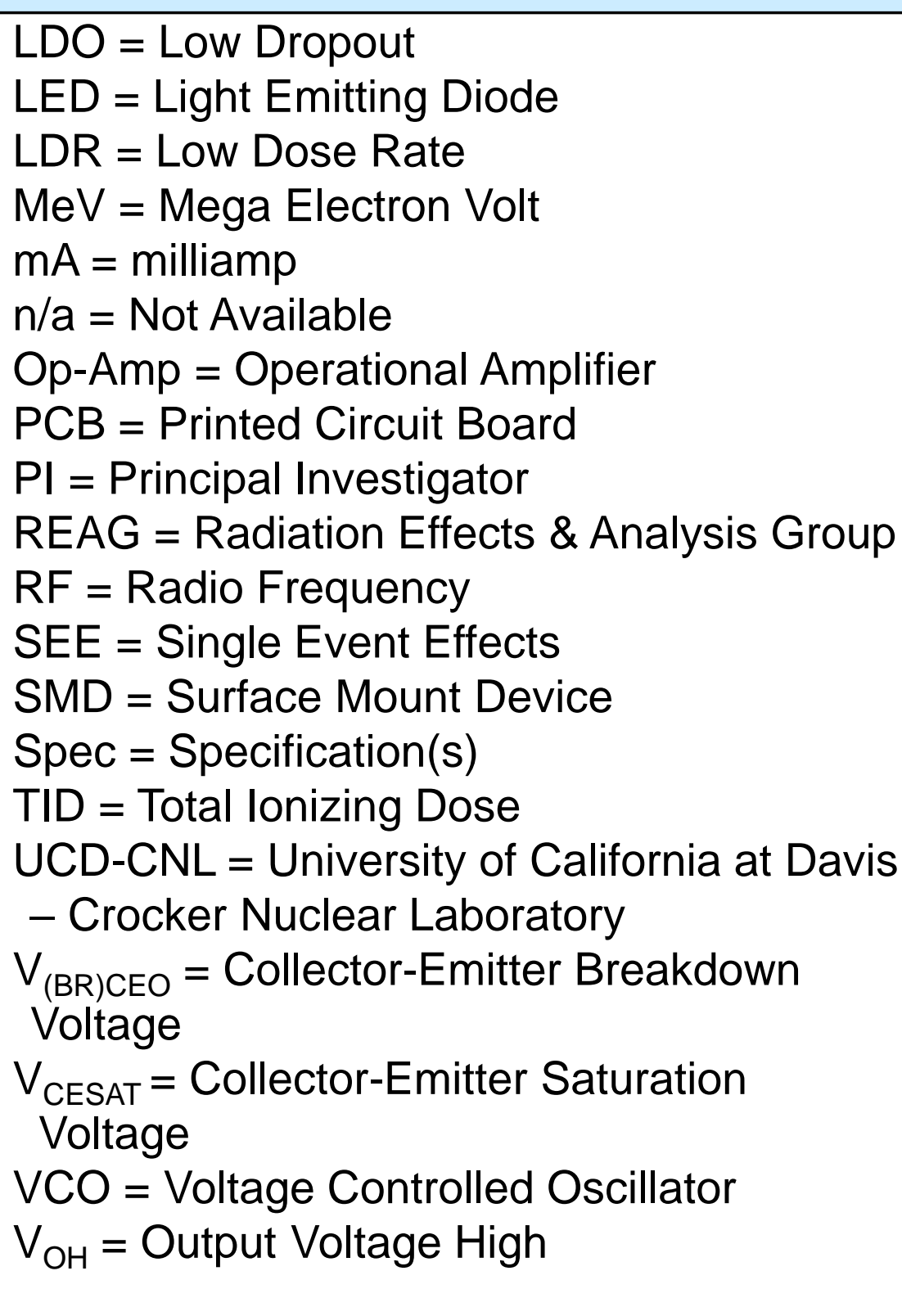 \\
\hline
\end{tabular}

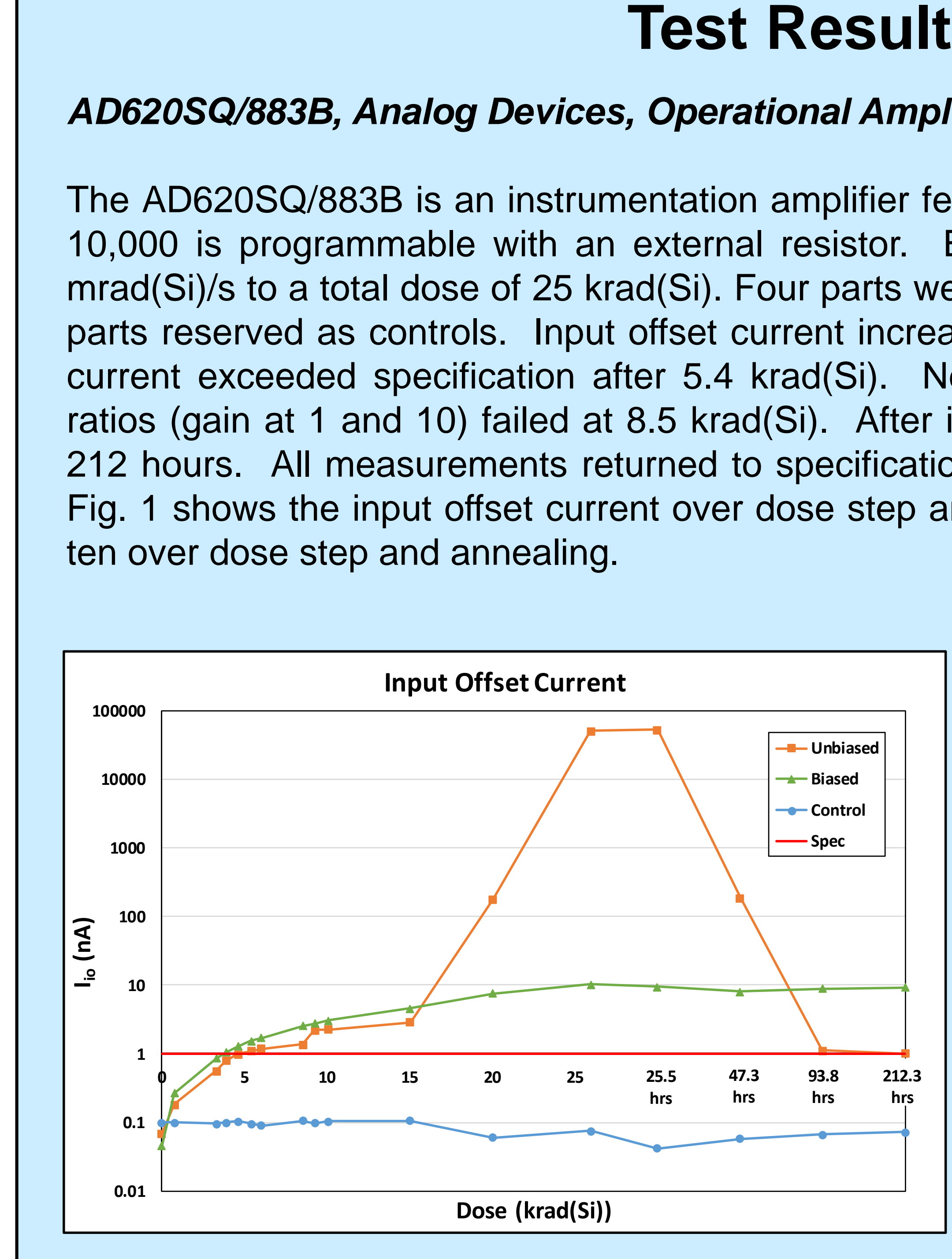

Test Results and Discussion

Figure 1. Input offset current vs.

OPB847, OPTEK Technology, Optical
Switch

The OPB847 is a $110-V$ slotted optical
switch with a gallium arsenide LED and silicon phototransistor. Ten parts were tested for DDD effects a t Crocker Nuclear
Laboratory at University of Califonia at
Davis $(U C D$. Davis (UCDC-CNL). Five were biased and
five were unbiased during irradiation, with
two parts reserved as controls.

On-state collector current (ILon) showed
an immediate decrease after the firs an immediate decrease after the firs
fluence step. This parameter exceeded the manufacturer's $\quad$ specification
consistently across all parts, at $2.18 \times 10^{10}$

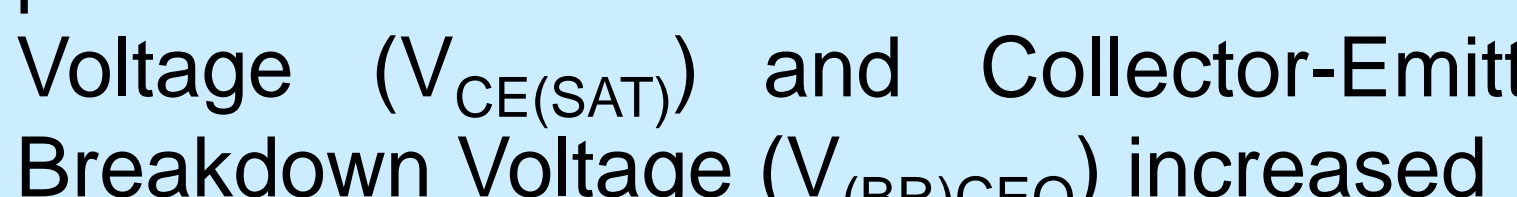

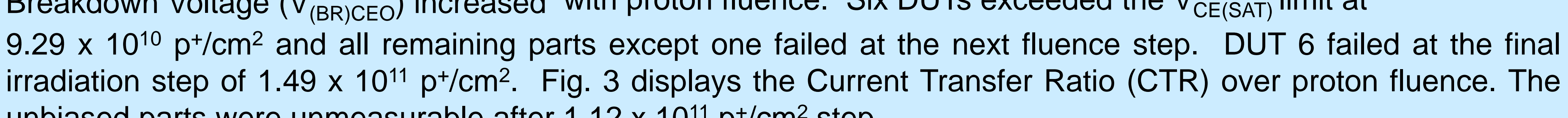
unbiased parts were unmeasurable after $1.12 \times 10^{11} \mathrm{p}^{+} / \mathrm{cm}^{2}$ step
und

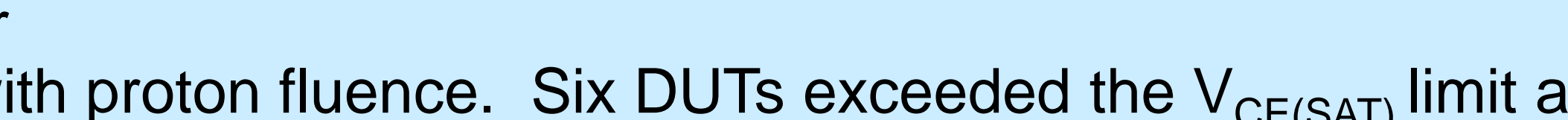

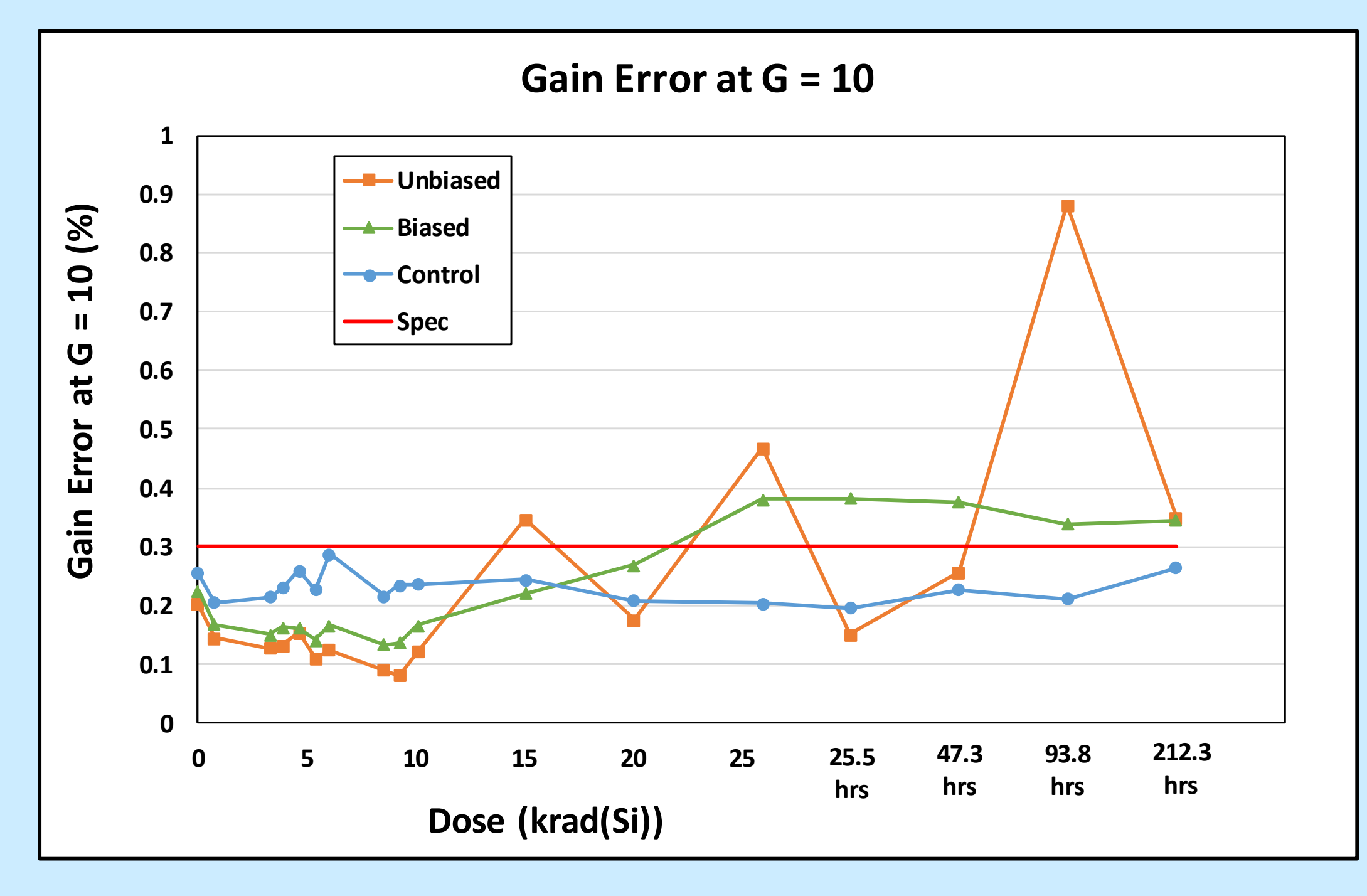

Figure 2. Gain error at gain $=10$ vs. dose (krad(Si)) and
annealing time.

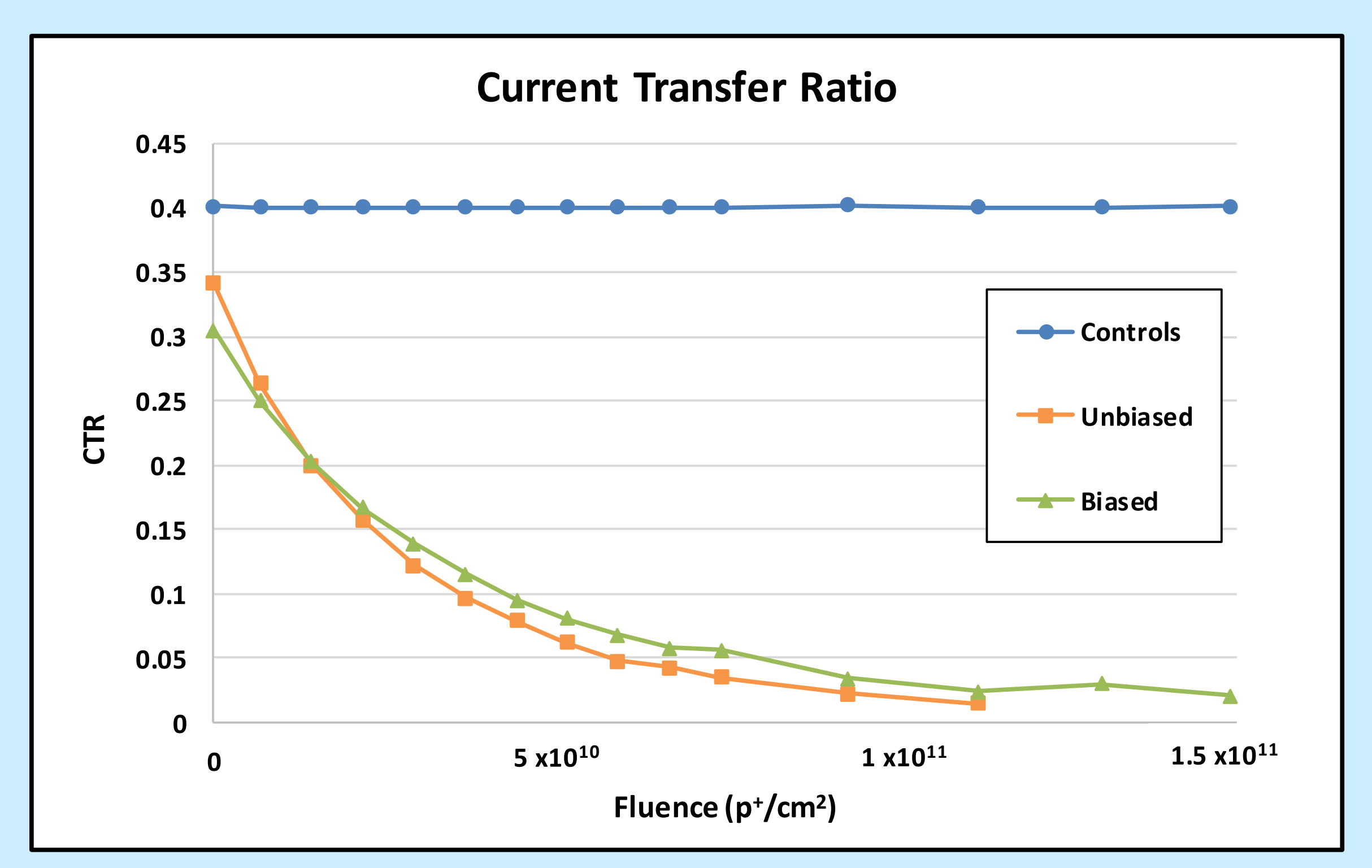

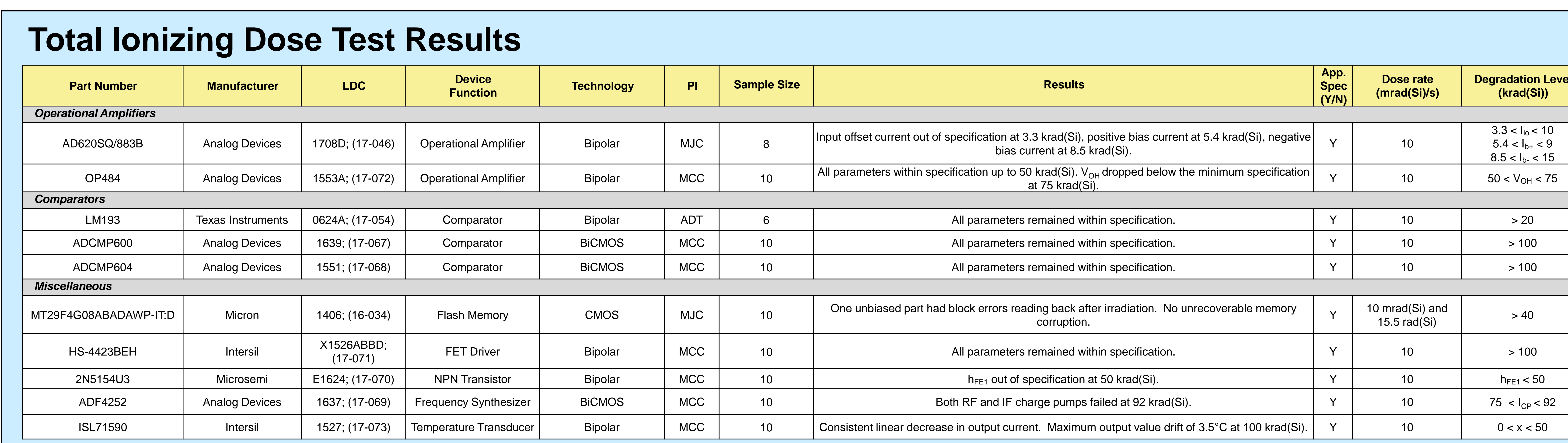

Displacement Damage Dose Test Results

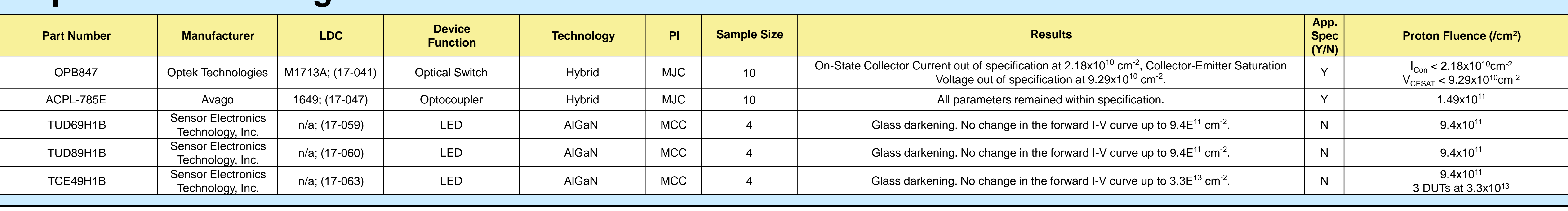

ADF4252, Analog Devices,
Frequency Synthesizer The ADF4252 is a dual RF/F
frequency synthesizer for wireless capaivers and transmitters,
cantiplying or dividing mplement a phase-locked loop When paired with an external
voltage controlled oscillator
VCO). The ADF4252 i is programmed with an SPIconpatible serial interface whic
contigures the on-chip mode

Due to the small package size and The logical high and low voltages, main supply voltage current, and
external component requirements,

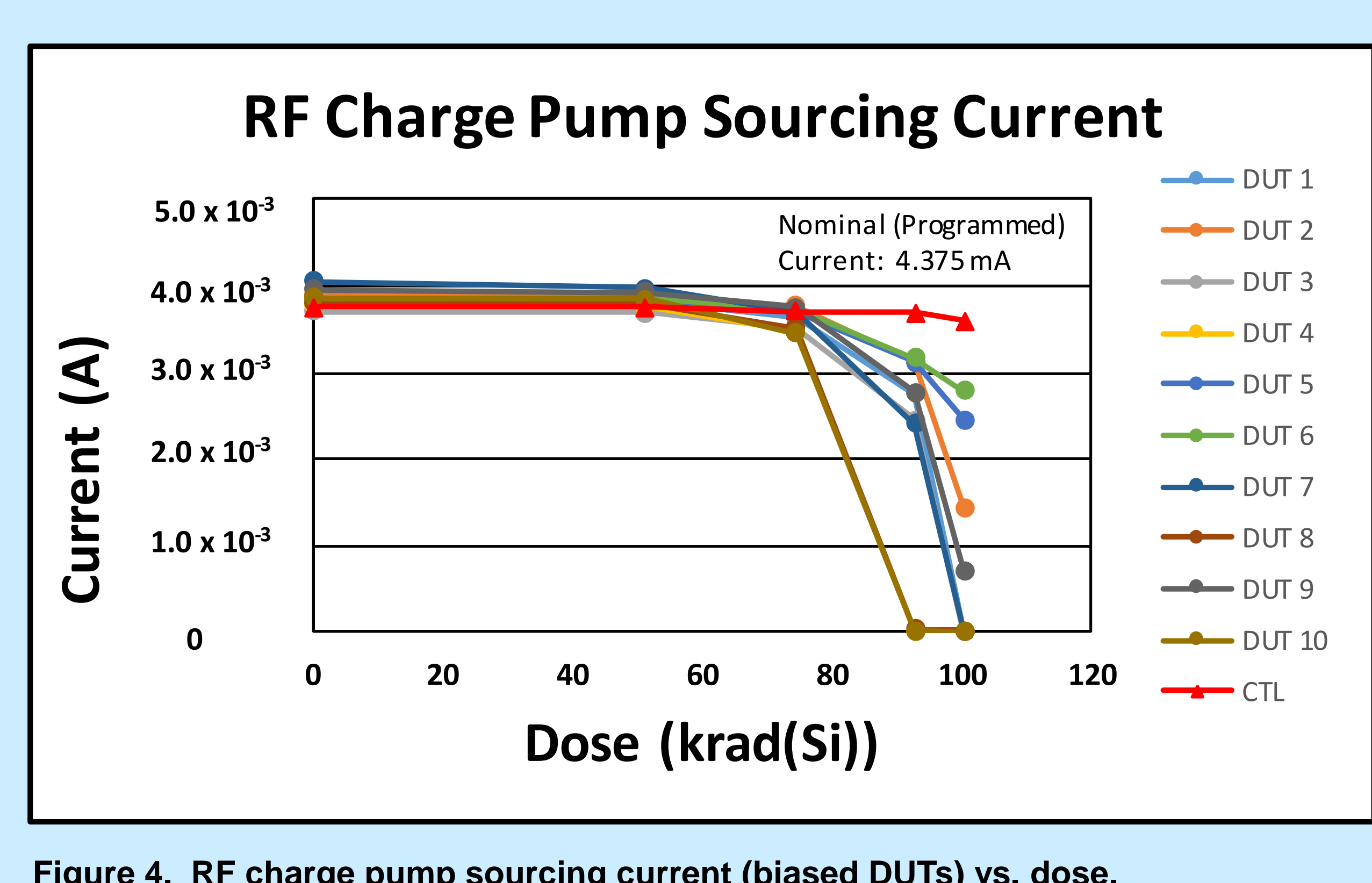
each device was soldered to a the charge pump supply current showed no appreciable
custom-designed PCB with a test degradation during irradiation. Only degradation was seen during circuit capable of measuring a irradiation on the following parameters; quiescent supply current
wpical set of performance and $75 \mathrm{krad}(\mathrm{Si})$ and charge pump supply current at $92 \mathrm{krad}(\mathrm{Si})$ typical set of performance and

Wwenty parts, with ten biased at Notably at $92 \mathrm{krad}(\mathrm{Si})$, the charge pumps of the biased parts began
nominal voltages and ten to fail. By the $100 \mathrm{krad}(\mathrm{Si})$ measurement, eight out of the ten grounded, were irradiated at a rate biased DUTs were no longer functioning. Fig. 4 shows the sudde of $10 \mathrm{mrad}(\mathrm{S}) / \mathrm{sh}$
$100 \mathrm{krad}(\mathrm{Si})$.

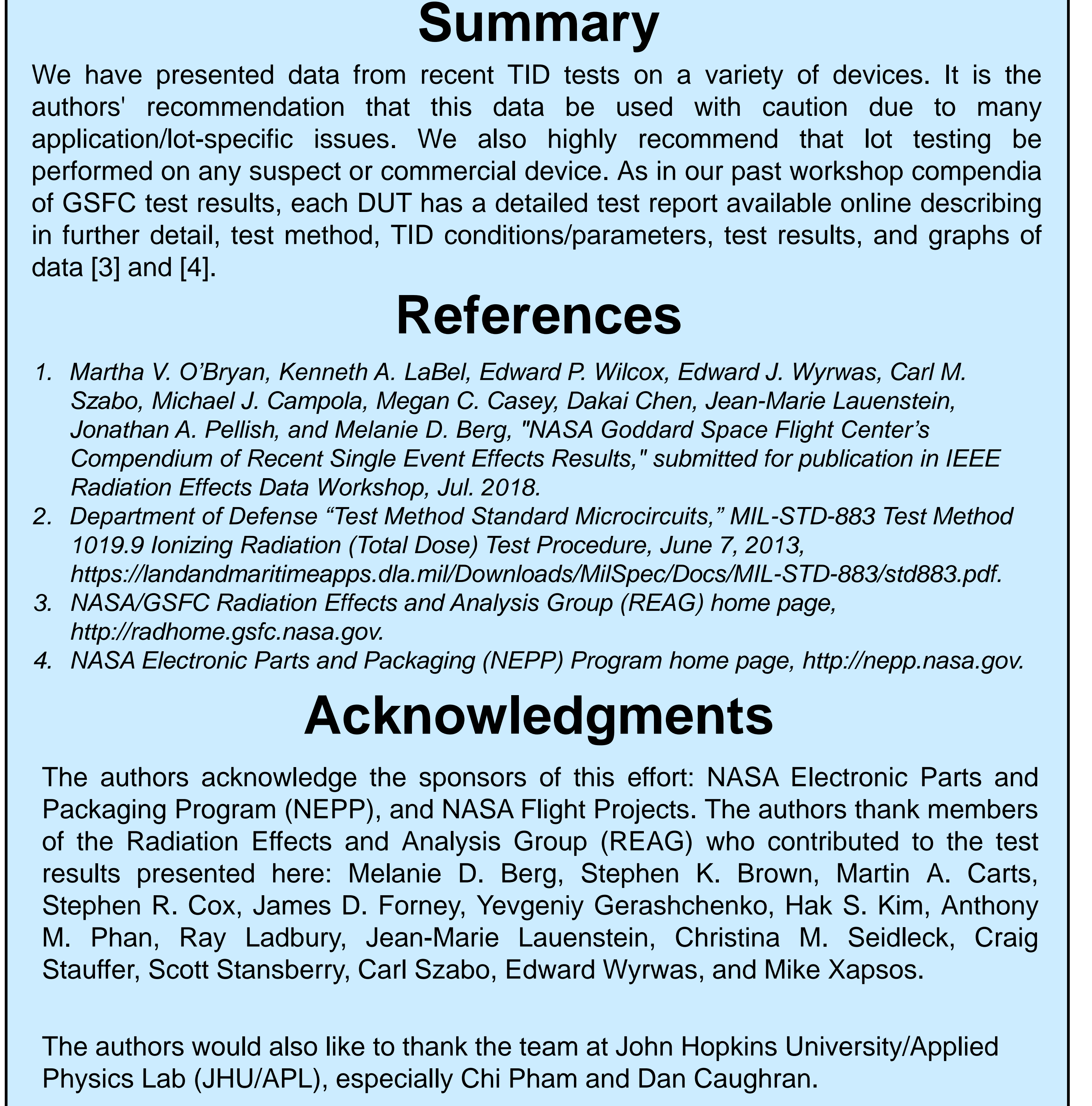

The authors would also like to thank the team at John Hopkins Univestur
Physics Lab (JHU/APL), especially Chi Pham and Dan Caughran.

$=$

\footnotetext{
\begin{tabular}{|l|l}
\hline To be presented by Alyson Topper at the 2018 Institute of Electrical and Electronics Engineers (IEEE) Nuclear and Space Radiation Effects Conference (NSREC), Kona, Hawaii, July 19, 2018.
\end{tabular}
} 